\title{
25 Research Square \\ Short-Term Effect of Poly Lactic Acid Microplastics Uptake by Earthworms, Eudrilus eugeniae.
}

\section{Shahad Khaldoon}

Universiti Sains Malaysia

Japareng Lalung ( $\square$ japareng@usm.my )

Universiti Sains Malaysia Pusat Pengajian Teknologi Industri https://orcid.org/0000-0001-5134-6456

Mahamad Hakimi lbrahim

Universiti Sains Malaysia

Mohamad Anuar Kamaruddin

Universiti Sains Malaysia

Mohd Firdaus Yhaya

Universiti Sains Malaysia

\section{Research Article}

Keywords: plastics, polylactic acid, microplastics, earthworms, Eudrilus eugeniae, vermicomposting

Posted Date: March 31st, 2021

DOI: https://doi.org/10.21203/rs.3.rs-298965/v1

License: (a) This work is licensed under a Creative Commons Attribution 4.0 International License. Read

Full License 


\section{Abstract}

The uptake of polylactic acid (PLA) microplastics, the most commonly used biodegradable plastics by earthworms Eudrilus eugeniae was investigated by observing their weight changes, biomass and the microplastics concentration after feeding them with a mixture of PLA and cow dung for 16 days at the concentrations of $0 \%, 10 \%, 30 \%, 60 \%$, and $80 \% \mathrm{w} / \mathrm{w}$ dry weight. The mortality rate of the earthworms for all the PLA concentrations during the 16 days of feeding period was $0 \%$. However, the microplastic affected the earthworms' weight significantly ( $P$-value 0.00027 ), especially at the concentration of $80 \%$ of PLA. The earthworms had the lowest weight gain at $80 \%$, followed by $60 \%, 30 \%$, and $10 \%$ of PLA, respectively. The earthworms subjected to $80 \%$ and $10 \%$ of PLA had a similar pattern with the control. This was perhaps due to the high organic matter in the worm's feed for the 10\% PLA and the digestion mechanisms, which led the earthworms to preserve their energy and become less active in the 80\% PLA, compared to all the other treatments. The PLA microplastics concentration factor (CF) in the vermicast was the highest at the $10 \%$ PLA compared to other treatments, because Eudrilus eugeniae did not degrade the PLA. This study concludes that even though PLA is a biopolymer-based, it cannot be bio- assimilated by the earthworm.

\section{Introduction}

Despite the practice of reducing, reusing, and recycling, plastics waste still poses a major problem due to its increasing diversity of properties and quantity. In 2013, plastics' global packaging production was 78 million tonnes, of which, $98 \%$ were produced using new non-recycled material (Geyer et al. 2017). Although $14 \%$ of these plastics were collected for recycling, only $2 \%$ were eventually recycled (Zhu, Yao, and Liu 2006). About $32 \%$ of the produced plastics end up in oceans or on land. In 2018, plastics' global production had reached 8.3 billion metric tons, and $76 \%$ of them became plastic waste. Only $9 \%$ of plastics produced was recycled, and $12 \%$ was incinerated. Approximately $79 \%$ of the plastics waste produced end up accumulating in a landfill or leaked into the environment (Geyer et al. 2017). By comparing the data from 2013 and 2018, it is evident that although the recycling rate has increased, the total volume of plastic waste produced has also been increased more than a hundred times.

The low recovery of plastics waste happened due to some reasons. Recycling facilities are expensive to built, and segregation requires extensive workforce. Regardless of the damaging effect towards the environment, these facilities are unable to recycle all type of plastics waste. For example, China's recycling facilities were the main cause of its enormous environmental pollution (Katx, 2019). On that note, China declared that they would stop importing plastics waste from any developed countries from July 2017. Due to this policy, other countries like Malaysia, Vietnam, Thailand, Indonesia, Taiwan, South Korea, Turkey, India and Poland were the new dumping sited for the developed counties (Asia 2019; BBC Reality Check Team 2019). This is one of the evidences of a global plastic waste issue. Neither all plastics can be recycled, nor their quality is the same after recycling (Achilias et al. 2007; Hopewell, Dvorak, and Kosior 2009; Schyns and Shaver 2020). Camacho and Karlsson (2000) reported that recycled plastics (food packaging plastics) were five times more hazardous contaminants (ethylbenzene and xylenes) than the non-recycled ones. Under these circumstances, bioplastics and biodegradable plastics have been promoted as an alternative to the non-degradable fossil-based 
Bioplastics are renewable and sustainable resources, known primarily by aliphatic bio-polyester such as polyhydroxyalkanoates (PHAs) or poly-3-hydroxybutyrate (PHB), polyhydroxy valerate (PHV), polyhydroxyalkanoate (PHH) and polylactic acid (PLA) (Altaf et al., 2007; Carus, 2012). There has been increasing demand on this type of plastics particularly the PLA (polylactic acid) and PHAs (polyhydroxyalkanoates). For example, the PLA production reached 140,000 metric tons of PLA per year in the USA by Blair facility alone. It was estimated that the global bioplastics production would reach 2.62 tonnes in 2023 (Rosevelt et al. 2013). This shows that PLA maybe one of the leading bioplastics for the future (Jamshidian et al., 2010). Due to the increase in the production of bioplastics, it is highly expected to contribute to plastic waste problem. Since most biodegradation testing of bioplastic are done in a controlled conditions for a start, it is highly impossible to ensure a complete degradation of these materials. Their accumulation and fragmentation into smaller particles in the environment is likely. These fine particles have been showing various impacts over ingested organisms (González-Pleiter et al. 2019; Shruti and KutralamMuniasamy 2019; Zuo et al. 2019).

In general, plastics are complex long-lasting materials. However, with prolonged exposure to weathering condition, plastics tend to shatter into smaller pieces, both in the open ocean or buried inside the soil. These fragmentations are known as microplastics with a size range starting from $5 \mathrm{~mm}$ to nanometres. These fine size particles possess high possibilities for interfering with the food chain and can cause damage to both flora and fauna (de Souza Machado et al., 2018a). The land is the primary source of plastics and microplastics, production and disposal, with estimated annual release of 4 to 23 times more than in the oceans (Horton et al. 2017; de Souza Machado et al. 2018). Despite the widespread of microplastics presence inland, long-term or large-scale monitoring data are limited. Sources of terrestrial of microplastics and its effect on terrestrial microorganism are overlocked until recent years (Rillig et al., 2017; de Souza Machado et al., 2018a).

Soil ecosystem facilitates a variety of services such as carbon sequestration, biogeochemical cycling, and promotion of biodiversity. There has been an increase in the documentation of microplastics polluting soil, with a high potential effect on soil biodiversity and function. There is also a lack of evidence on this pollutant destructive behaviour in the soil (de Souza Machado et al., 2018b). The earthworms positively affect the soil structure and the decomposition and mineralization of litter by breaking down organic matter and increasing soil fertility. Due to their impact on soil properties and their influence on the availability of resources for other species, including microorganisms and plants, earthworms are known as soil engineers. Nevertheless, less attention has been paid to their impacts on the soil ecosystem (Kooch and Jalilvand, 2008). Thus, the potential of earthworm for plastics degradation and toxicity is underexplored.

Microplastics can enter the soil ecosystems in a few different ways such as by mulching materials used in the agriculture, during the production of microplastics, secondary sources from the breaking down of plastics materials and sludge produced by wastewater treatment. A few researchers reported the possibilities of surface microplastics transported by the earthworms into the more in-depth soil profile (Huerta Lwanga et al. 2016; Matthias C. Rillig, Ziersch, and Hempel 2017; Yu et al. 2019; Zhang et al. 2018). Worms move particles in two ways; by the adhesion on the their body when it comes to contact with the pollutant, and by their cast as a result of ingestion. A higher concentration of microplastics has been detected in the L. Terrestris burrow compared to the surface area (Huerta Lwanga et al., 2016). Therefore, there is a potential effect of leaching microplastics to the groundwater throughout the earthworm burrows. 
The mortality of earthworms caused by petroleum and bio-based microplastics were observed in a few studies. For example, according to Cao et al. (2017), 2\% of polystyrene (PS) which is petroleum-based plastics mixed with the earthworms feed cause a significant inhibition to the growth of the earthworms. In the case of lowdensity Polyethylene (LDPE), the mortality rate of the earthworms was between $8-25 \%$ when the LDPE concentration was $28 \%$ and $60 \%$, as observed by Huerta Lwanga et al. (2017). Nevertheless, a contradictory result was observed by Zhang et al. (2018). In his study, exposure of the earthworms to LDPE films resulted in zero per cent mortality. This result might be caused by selective behavior of the earthworms toward their feed. Polylactic acid (PLA) is known as bio-based plastics. Even though the mortality rate was zero, the weight loss of worms subjected to PLA was evident (Alauzet et al. 2002). The earthworms were also unable to digest and consume the PLA as carbon source (Qi et al. 2018). Even though PLA is plant-based plastics, it shows resistance to degradation without exposure to hydrolysis degradation first. However, the two studies were conducted using PLA 50 and PLA 96, and any research on the effect of commercial PLA towards the fitness of Eudrilus eugeniae is yet to be conducted. Eudrilus eugeniae has a natural ability to colonize organic waste, with high endurance and handling resistance, possess tolerance to a wide range of environmental factors and capable of digestion and assimilation of organic matter (Kooch and Jalilvand, 2008).

The purpose of this research is to observe the possibility of Eudrilus eugeniae earthworms to degrade PLA microplastics, as well as the effect of different concentrations of PLA on their weight changes, growth rate and cast concentration factor (CF) when the specific concentration of PLA microplastics was added into their feed.

\section{Methodology}

\subsection{Material}

Twenty-five plastic containers with a diameter of $8.5 \mathrm{~cm}$, a height of $6.0 \mathrm{~cm}$, closed lid was used for the feeding experiment. Virgin polylactic acid, Grade PLA4032D were imported from Nature Works, USA by Innovative Pultrusion Sdn. Bhd. The PLA was ground to the required size of between 40 to $106 \mu \mathrm{m}$. Earthworms Eudrilus eugeniae were provided by the ECO- PRO laboratory in the School of Industrial Technology Universiti Sains Malaysia (USM). The cow dung was obtained from a cow farm in Balik Pulau, Penang, Malaysia.

\subsection{Media Preparation}

Pre-composted cow dung was used as a the primary feeding media., according to the methods by (Coulibaly et al.

2011; Manyuchi and Whingiri 2014). The cow dung was homogenized by passing them through a $2 \mathrm{~mm}$ and $800 \mu \mathrm{m}$ sieve to avoid selective feeding, as suggested by Sampedro and Whalen (2007) and immersed in water for 24 hours to remove insects and pressed inside a piece of cloth to remove excess water before usage. The PLA microplastics were mixed with cow the dung at five different concentrations, as shown in Table 1. A synthetic nylon-based cloth was placed on top of the media, which was a mixture of cow dung and PLA to attract the earthworms to cast on the top of the media as well as to collect and retain the moisture. 
Table 1

The ratio of PLA microplastics and cow dung mixture to obtain the desired percentage of PLA. The third column on the right shows the initial feed given to earthworm for each PLA percentage.

\begin{tabular}{|lll|}
\hline Percentage of PLA (\%) & PLA (g) & Cow dung (g) (dry weight) \\
\hline 80 & 28.0 & 35.0 \\
\hline 60 & 21.0 & 35.0 \\
\hline 30 & 10.5 & 35.0 \\
\hline 10 & 3.5 & 35.0 \\
\hline 0 & 0 & 35.0 \\
\hline
\end{tabular}

\section{Earthworms selection and adaptation stage}

The selection and adaptation methods of Eudrilus eugeniae earthworms were modified from (Pokarzhevskii et al., 2000). For this experiment, 25 individuals were selected from the vermicomposting units at ECO-PRO laboratory in the School of Industrial Technology, Universiti Sains Malaysia (Table 2). The earthworms were adapted to the new environment for seven days, with continuous monitoring of moisture content, feed, and mortality for every two days.

Table 2

Number of the earthworms per container, the weight and feeding rates used in the experiment

\begin{tabular}{|lllll|}
\hline $\begin{array}{l}\text { Number of } \\
\text { earthworms }\end{array}$ & $\begin{array}{l}\text { Average individual } \\
\text { weight (g) }\end{array}$ & $\begin{array}{l}\text { Minimum } \\
\text { individual weight } \\
\text { (g) }\end{array}$ & $\begin{array}{l}\text { Maximum } \\
\text { individual weight } \\
\text { (g) }\end{array}$ & $\begin{array}{l}\text { Feeding rate (wet } \\
\text { weight)/ unit }\end{array}$ \\
\hline 25 & $1.041 \pm 0.030$ & 0.97 & 1.1 & $60 \mathrm{~g} /$ container \\
\hline
\end{tabular}

\subsection{Feeding experiment}

A plastic container with a diameter of $8.5 \mathrm{~cm}$ and $6.0 \mathrm{~cm}$ height, with six holes was used. The cow dung and PLA microplastics mixture was placed into the container before an earthworm was added. Five replicates were used per treatment. The container was labelled and placed in a dark, closed box with $16 / 8$ ratio of light/ drank. The experiment was carried out for 16 days. Every four days, the earthworms were measured for their weight and checked for their feed moisture. After 16 days, the earthworm was subjected to gut voiding for 48 hours by placing them into an empty container. Five milliliters of distilled water was sprayed every two days to maintain the moisture. The cast was collected from the containers, placed them into a zip-locked bag and kept at $4^{\circ} \mathrm{C}$ for further analysis.

\subsection{The calculation for the concentration of PLA microplastics in the vermicast}

The concentration of PLA microplastics in the vermicast, in terms of cast concentration factor (CF), was calculated based on the work done by Huerta Lwanga et al., (2016): 


$$
C F=\frac{S_{P L}}{S_{S}}
$$

Where $S_{S}$ is the plastic fraction in the initial substrate, the fraction of plastic in the casts $\left(S_{P L}\right)$ was calculated by:

$$
S_{P L}=\frac{M_{P L}}{M_{c}}
$$

$M_{P L}$ and $M_{C}$ are the dry weight of the microplastic in the casts $(\mathrm{mg})$ and the collected cast's dry weight $(\mathrm{mg})$, respectively.

\subsection{Statistical Analysis}

Statistical analysis such as descriptive analysis, analysis of variance, and correlation analysis was performed using Excel 2016 (Microsoft office 2016). Descriptive analysis was present as mean, standard deviation, maximum and minimum values for different parameters. A one way and two ways Anova was perform to determine any significant differences between the parameters. Correlation analyses using Pearson Correlation Coefficient Formula was conducted to show the relationship between concentration of PLA and earthworms weight change.

\section{Result And Discussion}

\subsection{The $\mathrm{pH}$ values for the vermicast}

The average $\mathrm{pH}$ of all the treatments did not vary much from the control. However, the treatment with $60 \%$ PLA concentration significantly differed with $p<0.05$ (Table 3). For degradation to happen, a drop in $\mathrm{pH}$ value was expected due to the formation of lactic acid in the vermicast. The $\mathrm{pH}$ of vermicast produced by earthworms was neutral, indicating that the PLA microplastics in the vermicast did not undergo any degradation process.

The moisture content, $\mathrm{pH}$, and temperature are considered the most important environmental factors that influence the biodegradation of plastic materials and affect the earthworms' health. In the biodegradation process, moisture content affects the microbial activities and hydrolysis stage, which is crucial for polymers degradation (Müller, 2002). Earthworms activities and behaviors are positively affected by moisture because the water content of their body is about $90 \%$. Similarly, temperature and $\mathrm{pH}$ are also affecting the activities of both microbes and earthworms. $\mathrm{pH}$ affects the enzymes released by the microbes to break down organic matters. Earthworms are less tolerant to extreme acidic and alkaline soil condition, causing them to escape from their growth medium. This may lead to their death. Availability of certain nutrients such as carbon, nitrogen, potassium and calcium are strongly dependent on $\mathrm{pH}$ (Viljoen and Reinecke, 1989). Due to those reasons, the $\mathrm{CD}$ 's moisture content and $\mathrm{pH}$ value were $67.16 \pm 0.327 \%$ and $6.7 \pm 0.005$, respectively, as the cow dung used had already been composted. 
Table 3

$\mathrm{pH}$ of the vermicast produced by earthworms after 16 days of exposure to $10 \%, 30 \%, 60 \%$ and $80 \%$ concentrations of PLA microplastics

\begin{tabular}{|l|lll|}
\hline \multicolumn{1}{|l|}{ Percentage of cow dung (\%) } & Percentage of PLA (\%) & pH value (1:10) \\
\hline 100 & 0 & $6.96 \pm 0.017 \mathrm{~b}$ \\
\hline 90 & 10 & $6.97 \pm 0.008 \mathrm{~b}$ \\
70 & 30 & $6.92 \pm 0.005 \mathrm{~b}$ \\
\hline 40 & 60 & $6.85 \pm 0.005 \mathrm{a}$ \\
\hline 20 & 80 & $6.98 \pm 0.048 \mathrm{~b}$ \\
\hline * Different letters indicate significant differences amongst treatment, $\mathrm{a}>\mathrm{b}>\mathrm{c}(\mathrm{Anova}, P<0.05)$ \\
\hline
\end{tabular}

The PLA microplastics were recovered from the vermicast after 16 days of feeding. The concentration of the microplastics in the cast was significantly higher in the $10 \%$ of PLA (Fig. 1) than all the other treatment. A significant effect was observed between the CF and different PLA concentration, as shown in Table 4. This may be related to the digestion of organic matter, leading to an increase in the cast's microplastics concentration, compared to the organic matter. The concentration factor (CF) is expressed as the microplastics' ratio in the vermicast to microplastics in the feed. The cast concentration factor (CF) was the highest in 10\% PLA, which means the most efficient for PLA accumulation. It is perhaps because the organic matter ratio to the microplastics was the highest compared to the rest. After ingestion, an increase in the concentration of microplastics in the cast occurred due to the organic matter's consumption in the earthworms' guts. In contrast, the PLA was not digested and therefore excreted in its initial form. Microplastics' concentration in the cast by a factor of 0.9 leads to a higher risk of incorporating microplastic into the soil, which may leach to the groundwater. This shows that earthworms were not able to degrade the PLA microplastics after digestion. A similar result was observed by Lwanga et al. (2016) when L. terrestris cast concentration factor was the highest when the worms were subjected to the lowest concentration of LDPE microplastic. Compared to $10 \%$, the other treatment showed gradually lower cast concentration factor.

Table 4

One-way Anova analysis of variance of the CF and the different concentrations of PLA MPS.

\begin{tabular}{|llll|}
\hline PLA MPs concentration & P-Value & & \\
\hline & $10 \%$ & $30 \%$ & $60 \%$ \\
\hline $30 \%$ & $3.62 \mathrm{E}-06$ & & \\
\hline $60 \%$ & $2.28 \mathrm{E}-06$ & $5.18 \mathrm{E}-06$ & \\
\hline $80 \%$ & $2.26 \mathrm{E}-07$ & $3.10 \mathrm{E}-07$ & $4.3 \mathrm{E}-06$ \\
\hline
\end{tabular}

\subsection{The effect of PLA microplastics concentration towards the mortality and weight change of the earthworms}


The earthworms in this experiment were starved for 48 hours. After the starvation, they were fed with PLA for 16 days and starved again for the following 48 hours. During the 16 days of feeding, the earthworms subjected to $10 \%$ and $80 \%$ of PLA had a similar weight gain curve with the control. However, their weight changes significantly depending on the PLA concentration, with a P-value of 0.00107 (Table 5). It was positively correlated with the PLA concentration, as shown in Table 6. During the 16 days, the earthworms showed a steady weight increase for all treatment (Fig. 2). That may be because PLA microplastics were the contributing factor towards the earthworm's weight. A second gut voiding was conducted after the 16 days of feeding to conclude the effect of PLA on the earthworm's net weight, as in Table 7. ANOVA test shows a significant difference between the different concentration of PLA with time on the earthworm's weight gain within the same group, with a $P$-value of $1.64 \mathrm{E}-40$ (Table 5).

Table 5

Two-way ANOVA analysis of variance of the earthworms' weight change within 48 hours of gut voiding and 16 days of feeding on PLA for all different concentration.

\begin{tabular}{|lllll|}
\hline & Source of Variation & df & F & P-value \\
\hline Without gut voiding & within the group & 4 & 143.438 & $1.64 \mathrm{E}-40$ \\
\cline { 2 - 6 } & between group & 16 & 2.761 & 0.001074 \\
\hline with gut voiding & within the group & 6 & 143.438 & $3.66 \mathrm{E}-65$ \\
\cline { 2 - 5 } & between group & 24 & 2.761 & 0.00028 \\
\hline Significant difference at $P<0.05$ & & & \\
\hline
\end{tabular}

Table 6

The correlation analysis for the weight changes in different concentration of PLA microplastics with time

\begin{tabular}{|llllll|}
\hline & 1st day & 4th day & 8th day & 12th day & 16th day \\
\hline 1st day & 1 & & & & \\
\hline 4th day & 0.157557 & 1 & & & \\
\hline 8th day & 0.211906 & 0.671728 & 1 & & \\
\hline 12th day & 0.292728 & 0.773144 & 0.847879 & 1 & \\
\hline 16th day & 0.39303 & 0.587778 & 0.710034 & 0.846246 & 1 \\
\hline
\end{tabular}

After the 16 days of feeding, the weight gained by the earthworms in the different concentration of PLA used was in the sequence was $0 \%>60 \%>80 \%>10 \%>30 \%$, respectively. Then, the earthworms were subjected to 48 hours of guts voiding, and the weight of earthworms after the second gut voiding was compared to the weight after the first starvation. The result indicates that the weight gain change sequence was $0 \%>60 \%>10 \%>30 \%$ $>80 \%$ PLA. Since the control with $0 \%$ PLA results in the highest weight gain among all other PLA treatments, it shows that the cow dung was the main source of organic matters for the earthworms (Table 7). Therefore, it can be concluded that the net weight gain was due to the assimilation of the cow dung, and not the PLA 
microplastics that was mixed in the feed. This relationship became more significantly different by the gut voiding pre-treatment, and the $P$-value increased to 0.00028 (Table 5). This result shows that gut content impacts the earthworms' weight exposed to cow dung and PLA.

Table 7

Weight of the earthworm throughout gut voiding and feeding on PLA.

\begin{tabular}{|c|c|c|c|c|c|c|c|}
\hline $\begin{array}{l}\text { The } \\
\text { percentage } \\
\text { of PLA (\%) }\end{array}$ & $\begin{array}{l}\text { The initial } \\
\text { weight of } \\
\text { the } \\
\text { earthworm } \\
\text { (g) } \\
\text { A }\end{array}$ & $\begin{array}{l}\text { The } \\
\text { weight of } \\
\text { earthworm } \\
\text { after the } \\
\text { first } 48 \\
\text { hours of } \\
\text { gut } \\
\text { voiding (g) } \\
\text { B }\end{array}$ & $\begin{array}{l}\text { The } \\
\text { weight of } \\
\text { the } \\
\text { earthworm } \\
\text { after the } \\
\text { first } 48 \text { of } \\
\text { gut } \\
\text { voiding } \\
\text { followed } \\
\text { by feeding } \\
\text { on PLA (g) } \\
\text { for } 16 \\
\text { days } \\
\text { C }\end{array}$ & $\begin{array}{l}\text { The } \\
\text { weight of } \\
\text { earthworm } \\
\text { after the } \\
\text { first } 48 \\
\text { hours gut } \\
\text { voiding } \\
\text { followed } \\
\text { by } 16 \\
\text { days of } \\
\text { feeding } \\
\text { and a } \\
\text { second } \\
\text { 48-hour } \\
\text { gut } \\
\text { voiding (g) } \\
\text { D }\end{array}$ & $\begin{array}{l}\text { The } \\
\text { weight } \\
\text { of the } \\
\text { guts } \\
\text { load } \\
\text { after } \\
\text { the } \\
\text { second } \\
\text { gut } \\
\text { voiding } \\
\text { (g) } \\
\text { E }\end{array}$ & $\begin{array}{l}\% \text { weight } \\
\text { gain } \\
\text { based on } \\
\text { the initial } \\
\text { weight of } \\
\text { the } \\
\text { earthworm } \\
\text { after the } \\
16 \text { days of } \\
\text { feeding. } \\
\text { C-A }\end{array}$ & $\begin{array}{l}\text { \% weight } \\
\text { gain by } \\
\text { the } \\
\text { earthworm } \\
\text { after gut } \\
\text { voiding } \\
\text { D-B }\end{array}$ \\
\hline 0 & $\begin{array}{l}1.060 \pm \\
0.040 b\end{array}$ & $\begin{array}{l}1.016 \pm \\
0.072 a\end{array}$ & $\begin{array}{l}1.965 \pm \\
0.070 \mathrm{ab}\end{array}$ & $\begin{array}{l}1.475 \pm \\
0.104 a\end{array}$ & $\begin{array}{l}0.190 \\
\pm 0.127\end{array}$ & 85.392ab & $45.178 b$ \\
\hline 10 & $\begin{array}{l}1.022 \pm \\
0.015 b\end{array}$ & $\begin{array}{l}1.004 \pm \\
0.024 a\end{array}$ & $\begin{array}{l}1.651 \pm \\
0.110 \mathrm{ab}\end{array}$ & $\begin{array}{l}1.279 \pm \\
0.073 b\end{array}$ & $\begin{array}{l}0.372 \\
\pm 0.106\end{array}$ & $61.558 a$ & $27.408 a b$ \\
\hline 30 & $\begin{array}{l}1.038 \pm \\
0.004 b\end{array}$ & $\begin{array}{l}0.966 \pm \\
0.036 a\end{array}$ & $\begin{array}{l}1.533 \pm \\
0.081 a\end{array}$ & $\begin{array}{l}1.211 \pm \\
0.086 b\end{array}$ & $\begin{array}{l}0.322 \\
\pm 0.014\end{array}$ & $47.642 a b$ & $25.360 a b$ \\
\hline 60 & $\begin{array}{l}1.020 \pm \\
0.020 b\end{array}$ & $\begin{array}{l}0.962 \pm \\
0.018 a\end{array}$ & $\begin{array}{l}1.713 \pm \\
0.142 \mathrm{ab}\end{array}$ & $\begin{array}{l}1.264 \pm \\
0.086 b\end{array}$ & $\begin{array}{l}0.449 \\
\pm 0.084\end{array}$ & $67.912 b$ & $31.385 a b$ \\
\hline 80 & $\begin{array}{l}1.064 \pm \\
0.005 a\end{array}$ & $\begin{array}{l}1.036 \pm \\
0.022 a\end{array}$ & $\begin{array}{l}1.727 \pm \\
0.122 b\end{array}$ & $\begin{array}{l}1.220 \pm \\
0.098 b\end{array}$ & $\begin{array}{l}0.507 \\
\pm 0.193\end{array}$ & $62.308 \mathrm{ab}$ & $17.743 a$ \\
\hline
\end{tabular}

The guts content had a massive effect on the earthworms' weight after 48 hours of starvation (Table 7). The microplastics in the earthworms' diet had contributed to the extra weight gain by the earthworms, compared to the control. The guts content was the lowest in $0 \%$ concentration of PLA and the highest at $80 \%$, which was about 2.6 times higher than the control. That was the cause for the weight of the earthworms to be significantly dropping after the starvation. Eudrilus eugeniae were unable to utilize the PLA microplastics as a source of organic matter in this study.

Similarly, in a study by Alauzet et al. (2002), a different earthworm species, Eisenia andrei was unable to digest PLA (PLA 96 and PLA 50) they consumed. Nevertheless, MPs derived from biodegradable plastics (plastics material label as PLA material) that has been mixed with the sediment and placed on the surface of the sediment enhanced the dry weight of the Lumbriculus variegatus (freshwater worms). The MPs mixed with the sediment caused harmful effects than layered MP, as observed by Klein et al.( 2021). However, a study done by Huerta Lwanga et al.( 2018) reported that Eisenia andrei was able to digest low-density polyethene (LDPE). 
These studies have shown that although the LDPE is a petroleum-based plastic, the worms could break them upon digestion. In contrast, although the PLA is plant-based, the worms could not break them after digestion. The result is contrary to the assumption that plant-based plastic is biodegradable, while their petroleum-based counterpart is not.

Our study concluded that the PLA microplastics eaten by the earthworms were indigested particles and cannot be used as carbon sources. Therefore, the plant-based PLA microplastic is not biodegradable using earthworms, Eudrilus eugeniae. That indicated the biodegradable plastics might not necessarily be a better alternative for conventional plastics.

\section{Conclusion}

In this study, different concentration of PLA microplastics was added in the feeding media for Eudrilus eugeniae. The mortality was $0 \%$ for all treatments, even though they were able to ingest the microplastics and egest in their cast. The worms were unable to bio-assimilate the microplastics since, perhaps because their feed content is a simpler form of organic matter, which is easier to digest than the microplastic. The PLA has affected the earthworm's weight, and may even be the digestive system or the guts load. They were able to adapt to the existing PLA microplastics in the media within the short-term exposure, even if they could not degrade and used it as the source of their organic matter. In conclusion, PLA had impacted the earthworms' weight, and the CF had indicated the presence of a high concentration of PLA in the vermicast. It is not biodegradable with respect to using Eudrilus eugeniae earthworms as an agent for degradation.

\section{Declarations}

\section{Ethics approval and consent to participate}

All institutional and national guidelines for the care and use of laboratory animals were followed

\section{Consent for publication}

Not applicable

\section{Availability of data and materials}

The data that support the findings of this study are available from the corresponding author upon reasonable request

\section{Competing interests}

The author declares no conflict of interest

\section{Funding}




\begin{tabular}{ll} 
Funder & Grant number \\
\hline Universiti Sains Malaysia & 304/PTEKIND/6316034, \\
& 203/PTEKIND/6711437.
\end{tabular}

MRUN TRANSLATIONAL RESEARCH GRANT (USM-MTUN-MCUN) 304/PTEKIND/656202

\section{Authors' contributions}

\begin{tabular}{ll} 
Author & Description of interest \\
\hline Japareng Lalung & Supervision, Validation, Reviewing, Editing, and Resources. \\
\hline $\begin{array}{l}\text { Mahamad Hakimi } \\
\text { lbrahim }\end{array}$ & Supervision, Validation, Reviewing, Editing, Resources and Funding acquisition \\
\hline $\begin{array}{l}\text { Mohamad Anuar } \\
\text { Kamaruddin }\end{array}$ & Funding acquisition \\
\hline Mohd Firdaus Yhaya & Supervision \\
\hline Shahad khaldoon & $\begin{array}{l}\text { Conceptualization, Methodology, Software, Data curation, Writing- Original draft } \\
\text { preparation, Formal analysis. }\end{array}$
\end{tabular}

\section{Acknowledgements}

We thank Universiti Sains Malaysia for providing us with research grant (304/PTEKIND/6316034), (304/PTEKIND/656202) and (203/PTEKIND/6711437).

\section{References}

1. Alauzet N, Garreau H, Bouche' M, Vert M (2002) Earthworms and the Degradation of Lactic Acid-Based Stereocopolymers. J Polym Environ 10:53-58

2. Achilias DS, Roupakias C, Megalokonomos P, Lappas AA, Antonakou V (2007) 'Chemical Recycling of Plastic Wastes Made from Polyethylene (LDPE and HDPE) and Polypropylene (PP)'. J Hazard Mater 149(3):536-542

3. Altaf M, Venkateshwar M, Srijana M, Reddy G (2007) 'An Eco- Nomic Approach for L-(+) Lactic Acid Fermentation by Lactoba- Cillus Amylophilus GV6 Using Inexpensive Carbon and Nitrogen Sources'. J Appl Microbiol 103:372-380

4. Asia (2019) 'Malaysia to Return 3,000 Tonnes of Plastic Waste to Countries of Origin, Says Importers Are "Traitors"'. Channel News Asia

5. BBC Reality Check Team (2019) 'Why Some Countries Are Shipping Back Plastic Waste'. BBC News. Retrieved 6 January 2021 https://www.bbc.com/news/world-48444874 
6. Camacho, Walker and Sigbritt Karlsson (2000) 'Quality-Determination of Recycled Plastic Packaging Waste by Identification of Contaminants by GC-MS after Microwave Assisted Extraction (MAE)'. Polym Degrad Stab 71(1):123-134

7. Carus M (2012) 'Growth in PLA Bioplastics: A Production Capacity of over 800,000 Tonnes Expected by 2020'. Nova Institute 1-2

8. Coulibaly SS, Kouadio I, Kouassi, Ebagnerin J, Tondoh, Zoro BIA (2011) 'Impact of the Population Size of the Earthworm Eudrilus Eugeniae (Kinberg) on the Stabilization of Animal Wastes during Vermicomposting'. Philippine Agricultural Scientist 94(4):359-367

9. Fründ H-C, Butt K, Capowiez Y, Eisenhauer N, Emmerling C, Ernst G, Potthoff M, Martin Schädler, and Stefan Schrader. 2010. 'Using Earthworms as Model Organisms in the Laboratory: Recommendations for Experimental Implementations'. Pedobiologia 53(2):119-25

10. Van Gestel CAM, Weeks JM (2004) 'Recommendations of the 3rd International Workshop on Earthworm Ecotoxicology, Aarhus, Denmark, August 2001'. Pp. 100-105 in Ecotoxicology and Environmental Safety. Vol. 57. Academic Press

11. Geyer R, Jambeck JR, Kara Lavender Law (2017) 'Production, Use, and Fate of All Plastics Ever Made'. Science Advances 3(7):e1700782

12. González-Pleiter M, Pulido-Reyes MTamayo-Belda,G, Amariei G, Leganés F, Roberto Rosal, and Francisca Fernández-Piñas. 2019. 'Secondary Nanoplastics Released from a Biodegradable Microplastic Severely Impact Freshwater Environments'. Environmental Science: Nano 6(5):1382-92

13. Hopewell J, Dvorak R, and Edward Kosior (2009) 'Plastics Recycling: Challenges and Opportunities'. Philosophical Transactions of the Royal Society B: Biological Sciences 364(1526):2115-2126

14. Horton AA, Walton A, Spurgeon DJ, Lahive E, Svendsen C (2017) 'Microplastics in Freshwater and Terrestrial Environments: Evaluating the Current Understanding to Identify the Knowledge Gaps and Future Research Priorities'. Sci Total Environ 586:127-141

15. Huerta Lwanga, Esperanza H, Gertsen H, Gooren P, Peters T, Salánki, Martine van der Ploeg, E, Besseling AA, Koelmans, and Violette Geissen. 2016. 'Microplastics in the Terrestrial Ecosystem: Implications for Lumbricus Terrestris (Oligochaeta, Lumbricidae)'. Environmental Science \& Technology 50(5):2685-91

16. Huerta Lwanga, Esperanza H, Gertsen H, Gooren P, Peters T, Salánki, Martine van der Ploeg, E, Besseling AA, Koelmans, and Violette Geissen. 2017. 'Incorporation of Microplastics from Litter into Burrows of Lumbricus Terrestris'. Environmental Pollution 220:523-31

17. Jamshidian M, Tehrany EA, Imran M, Jacquot M, Stéphane, Desobry (2010) 'Poly-Lactic Acid: Production, Applications, Nanocomposites, and Release Studies'. Comprehensive Reviews in Food Science Food Safety 9(5):552-571

18. Katx C (2019) 'Piling Up: How China's Ban on Importing Waste Has Stalled Global Recycling [Available at: Https://E360.Yale.Edu/Features/Piling-up-How-Chinas-Ban-on-Importing-Waste-Has-Stalled-GlobalRecycling]'. Yale E360

19. Kooch $Y$ and Hamid Jalilvand (2008) 'Earthworms as Ecosystem Engineers and the Most Important Detritivors in Forest Soils'. Pak J Biol Sci 11(6):819-825

20. Manyuchi MM, Whingiri E (2014) 'Original Research Article Effect of Vermicomposting Period, Substrate Quantity, Cow Dung Composition and Their Interactions on Eisenia Fetida during Vermicomposting'. 
International Journal of Current Microbiology Applied Sciences 3(8):1021-1028

21. Müller R-J (2002) 'Biodegradability of Polymers: Regulations and Methods for Testing'. Pp. 365-74 in Biopolymers Online

22. Alauzet N, Garreau H, Bouche' M, Vert M (2002) 'Earthworms and the Degradation of Lactic Acid-Based Stereocopolymers'. J Polym Environ 10(1-2):53-58

23. Pokarzhevskii AD, Nico M, Van Straalen, Semenov AM (2000) 'Agar as a Medium for Removing Soil from Earthworm Guts'. Soil Biol Biochem 32(8-9):1315-1317

24. Qi Y, Yang X, Pelaez AM, Lwanga EH, Beriot N, Gertsen H, Garbeva P, Violette Geissen (2018) 'Macro- and Micro- Plastics in Soil-Plant System: Effects of Plastic Mulch Film Residues on Wheat (Triticum Aestivum) Growth'. Science of The Total Environment 645:1048-1056

25. Rillig MC, Rosolino Ingraffia, Anderson A, De Souza M (2017) 'Microplastic Incorporation into Soil in Agroecosystems'. Front Plant Sci 8:1805

26. Rillig MC, Ziersch L, and Stefan Hempel (2017) 'Microplastic Transport in Soil by Earthworms'. Sci Rep $7(1): 1362$

27. Rosevelt C, Los Huertos M, Garza C, Nevins HM (2013) 'Marine Debris in Central California: Quantifying Type and Abundance of Beach Litter in Monterey Bay, CA'. Mar Pollut Bull 71(1-2):299-306

28. Sampedro L, Whalen JK (2007) 'Changes in the Fatty Acid Profiles through the Digestive Tract of the Earthworm Lumbricus Terrestris L'. Appl Soil Ecol 35(1):226-236

29. Schyns ZOG, Shaver MP (2020) 'Mechanical Recycling of Packaging Plastics: A Review'. Macromolecular Rapid Communications 2000415

30. Shruti VC, Gurusamy Kutralam-Muniasamy (2019) 'Bioplastics: Missing Link in the Era of Microplastics'. Science of The Total Environment 697:134139

31. de S Machado, Abel A, Kloas W, Zarfl C, Hempel S, Rillig MC (2018) 'Microplastics as an Emerging Threat to Terrestrial Ecosystems'. Glob Change Biol 24(4):1405-1416

32. De Souza MacHado A, Abel CW, Lau J, Till W, Kloas A, Lehmann R, Becker, Rillig MC (2018) 'Impacts of Microplastics on the Soil Biophysical Environment'. Environ Sci Technol 52(17):9656-9665

33. Viljoen SA, Reinecke AJ (1989) 'Life-Cycle of the African Nightcrawler, Eudrilus Eugeniae (Oligochaeta)'. South African Journal of Zoology 24(1):27-32

34. Yu M, Ploeg MVanD, Lwanga EH, Yang X, Zhang S, Ma X, Ritsema CJ, Violette Geissen (2019) 'Leaching of Microplastics by Preferential Flow in Earthworm (Lumbricus Terrestris) Burrows'. Environ Chem 16(1):3140

35. Zhang L, Sintim HY, Andy I, Bary, Douglas G, Hayes LC, Wadsworth MB, Anunciado, Markus Flury (2018) 'Interaction of Lumbricus Terrestris with Macroscopic Polyethylene and Biodegradable Plastic Mulch'. Science of The Total Environment 635:1600-1608

36. Zhu L, Yao KL, Liu ZL (2006) 'First-Principles Study of the Polar (111) Surface of Fe304'. Phys Rev B 74(3):035409

37. Zuo L, Zi HX, Li L, Lin YX, Diao SZengH, Liu S, Zhang ZY, Xiang Rong Xu (2019) 'Sorption and Desorption of Phenanthrene on Biodegradable Poly(Butylene Adipate Co-Terephtalate) Microplastics'. Chemosphere 215:25-32 
Figures

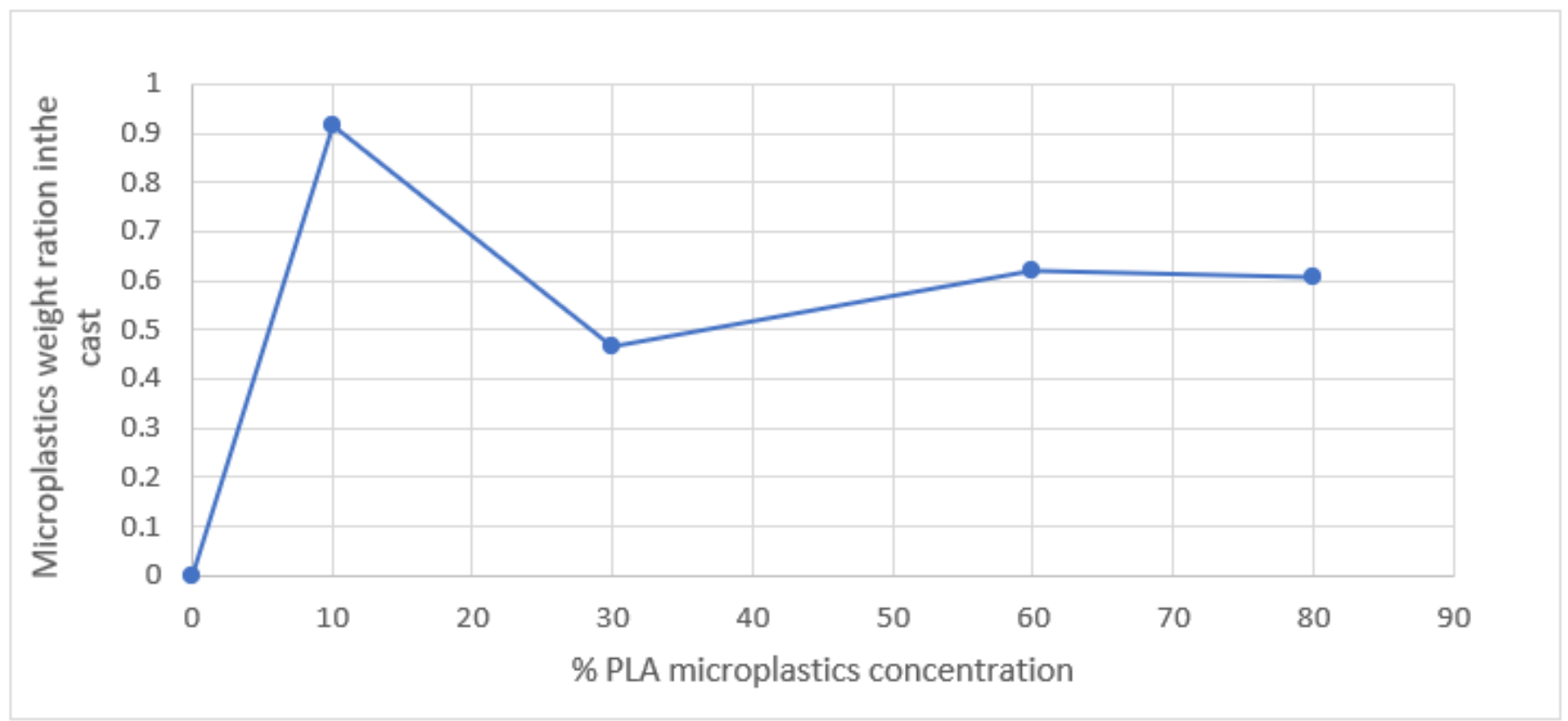

Figure 1

Cast concentration factor (CF) for different concentration of PLA microplastics.

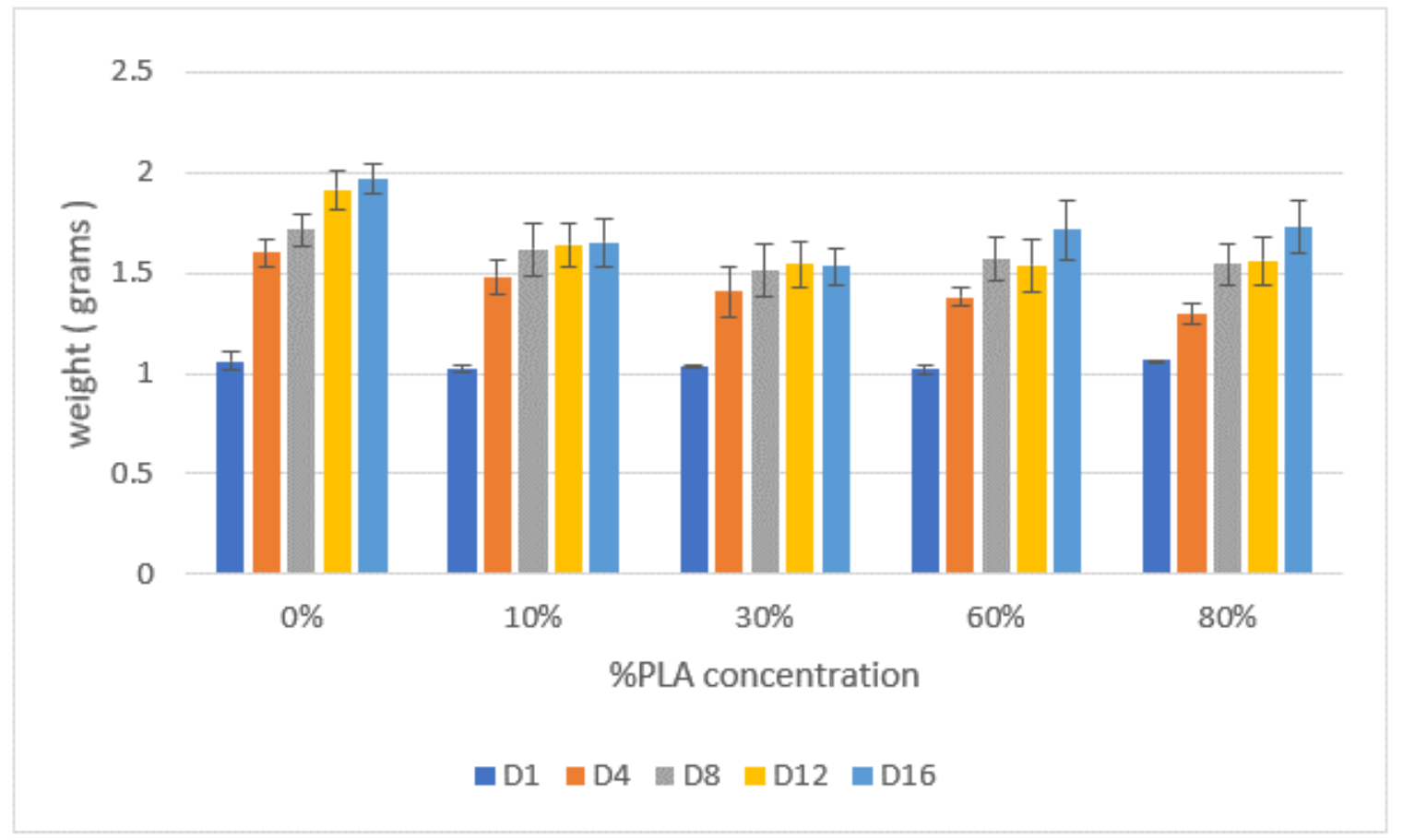

Figure 2

The effect of the different concentration of PLA microplastics on the earthworm weight over time. The weight was measured every four days during the 16 days of the feeding experiment. 


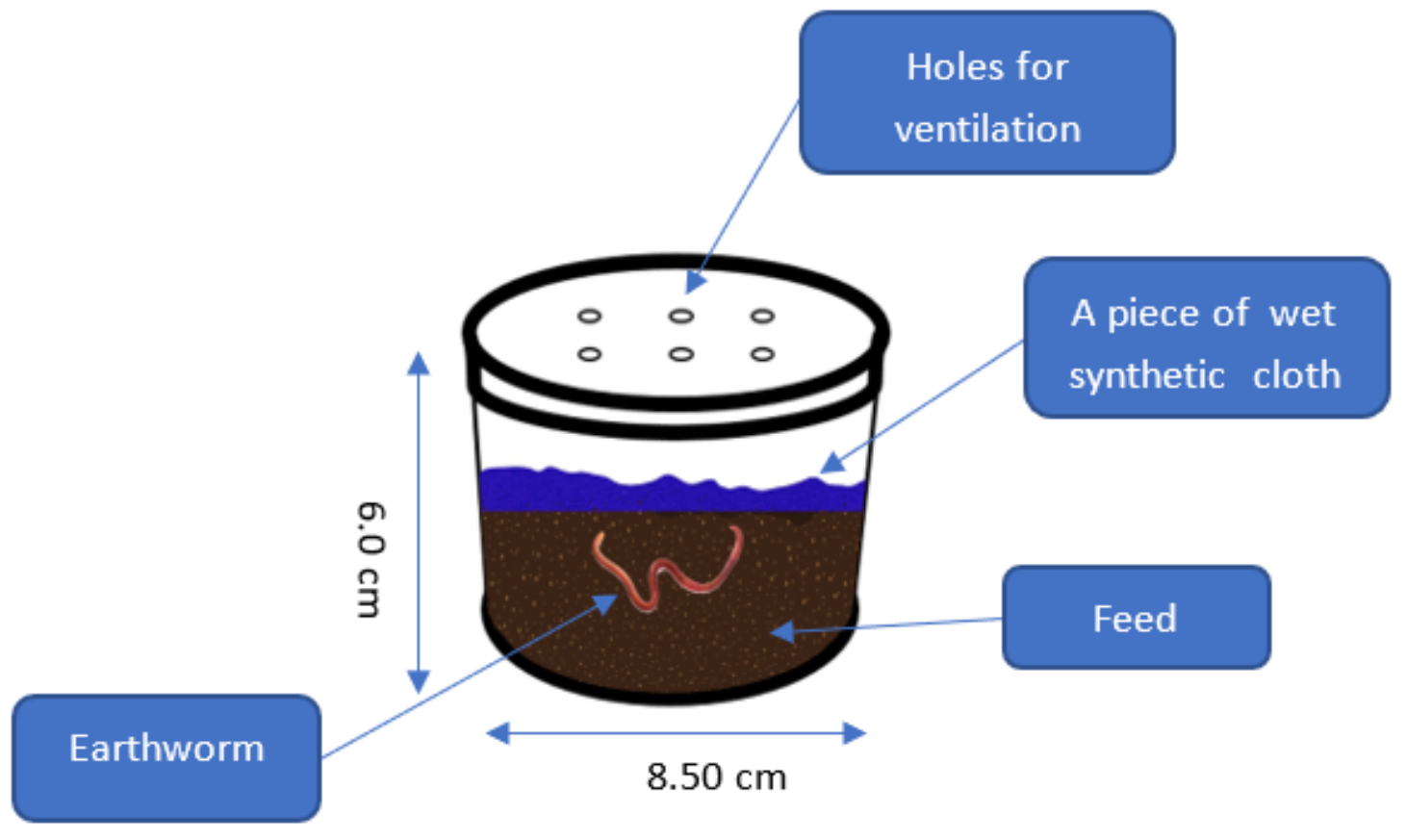

\section{Figure 3}

Illustration of the unit set up for feeding and toxicity test for individual earthworms fed with PLA microplastics and cow dung (illustrated by Shahad Khaldoon).

\section{Supplementary Files}

This is a list of supplementary files associated with this preprint. Click to download.

- GraphicalAbstract.docx

- Highlights.docx 